\title{
A avaliação escolar no Ensino Secundário em Moçambique e os indícios de uma educação excludente
}

Aristides Silvestre Culimua ${ }^{1}$

\section{Resumo}

Este artigo se propõe a analisar as implicações decorrentes dos processos de avaliação vigentes no Ensino Secundário Geral do $2^{\circ}$ ciclo - ESG2, em Moçambique. Teoricamente, mobilizaram-se as categorias sociológicas de educação, nomeadamente, os ritos de instituição/consagração social, e o capital cultural/linguístico. Tais conceitos assumiram um papel proeminente para o desvelamento da essência dos princípios que subjazem o Regulamento de Avaliação adotado no ESG2. Metodologicamente, trata-se de um estudo de natureza qualitativa com alguns retoques quantitativos, servindo-se do método hermenêutico, o qual possibilitou a análise das fontes bibliográficas e documentais inerentes à educação moçambicana. Os argumentos aqui discorridos sugerem o estabelecimento de políticas educacionais mais condizentes à precariedade social e ao capital cultural/linguístico que marcam a grande maioria de alunos, assim como à promoção da desejável inclusão e justiça escolar no interior do sistema de ensino, prevista legalmente.

\section{Palavras-chave}

ESG2. Regulamento de avaliação. Educação excludente. Sociologia de educação. Moçambique.

\footnotetext{
${ }^{1}$ Doutorando em Educação na Universidade do Estado de Santa Catarina, Brasil; bolsista CAPES PEC-PG. Email: arisculimua@gmail.com.
} 


\title{
School evaluation in Secondary Education in Mozambique and the evidence of an exclusive education
}

Aristides Silvestre Culimua ${ }^{2}$

\begin{abstract}
This article aims to analyze the implications arising from the current evaluation processes in the General Secondary Education of the $2^{\text {nd }}$ cycle - ESG2 in Mozambique. Theoretically, education sociological categories were mobilized, namely, the rites of institution/social consecration, and cultural/linguistic capital. Such concepts have taken on a prominent role in unveiling the essence of the principles underlying the Evaluation Regulation adopted in ESG2. Methodologically, it is a qualitative study with some quantitative touches, using the hermeneutic method, which made it possible to analyze the bibliographic and documentary sources inherent to Mozambican education. The arguments discussed here suggest the establishment of educational policies more consistent with the social precariousness and cultural/linguistic capital that mark the vast majority of students and the promotion of the desirable inclusion and school justice within the teaching system, legally provided.
\end{abstract}

\section{Keywords}

ESG2. Evaluation regulation. Excluding education. Sociology of education. Mozambique.

\footnotetext{
${ }^{2} \mathrm{PhD}$ student in Education, State University of Santa Catarina, State of Santa Catarina, Brazil; CAPES PEC-PG scholarship holder. E-mail: arisculimua@gmail.com.
} 


\section{Introdução}

Geograficamente, este estudo se refere ao Moçambique, país localizado na costa sudeste do continente africano, mais precisamente na região da África Austral. Historicamente, à semelhança das antigas colônias portuguesas na África, o país esteve imerso em um regime educacional discriminatório imposto pelo governo colonial. Tratou-se, efetivamente, de um sistema educacional de caráter excludente, e por isso, favorável à reprodução de desigualdades sociais, em prejuízo de uma grande maioria africana.

Do ponto de vista de acesso à educação, a dimensão estratificante do Estado Colonial Português em Moçambique se materializou, essencialmente, com a concentração de estabelecimentos escolares nas zonas urbanas, que eram os centros de maior aglomerado populacional ocidental (GASPERINI, 1989).

A revisão do modelo de educação colonial só viria a se concretizar oficialmente no Moçambique pós-independente, com base na lei 4/83 de 23 de março de 1983, que instituiu o primeiro Sistema Nacional de Educação (SNE) autônomo (MOÇAMBIQUE, 1983), o qual estabelecia que

a educação é um direito e um dever de todo o cidadão, o que se traduz na igualdade de oportunidades de acesso a todos os níveis de ensino, e na educação permanente e sistemática de todo o povo; a educação é dirigida, planificada e controlada pelo Estado, que garante a sua universalidade e laicidade no quadro da realização dos objetivos fundamentais consagrados na constituição. (MOÇAMBIQUE, 1983, p. 14).

Os dois princípios gerais relativos ao primeiro SNE representaram formalmente uma tentativa de revisão do sistema educativo colonial, empreendendo uma massificação da educação para todos/as, inscrita na materialização dos princípios ideológicos socialistas que orientaram a sociedade moçambicana entre os anos 1975 e 1990 (MACHEL, 1980 apud BASÍLIO, 2010). Entretanto, a abertura do país à economia liberal determinou incontornavelmente a revisão da lei ${ }^{\circ}$ 4/83 do SNE (MOÇAMBIQUE, 1983) por meio da lei $n^{\circ}$ 6/92 de 6 de maio de 1992 (MOÇAMBIQUE, 1992).

Considerando o contexto moçambicano, o objetivo central deste estudo é analisar as implicações decorrentes dos processos de avaliação escolar em vigor no Ensino Secundário Geral do $2^{\circ}$ ciclo - ESG2. As razões que impulsionaram o empreendimento deste estudo estão ligadas, por um lado, à sua potencialidade de vir a desnudar os mecanismos ocultos 
(excludentes) subjacentes ao Regulamento de Avaliação aplicado no ESG2 (MOÇAMBIQUE, 2018b), e por outro, à sua possibilidade de fomentar debates sobre os desafios que se colocam à educação moçambicana.

Conforme colocado previamente, os argumentos discorridos neste trabalho buscam os seus fundamentos teóricos nos estudos franceses da sociologia da educação (BOURDIEU, 1998a, 1998b; BOURDIEU; CHAMPAGNE, 1998; DUBET, 2003; BOURDIEU; PASSERON, 2008; 2018). A justificativa para a escolha desse referencial está na sua potencialidade de vir a permitir uma leitura sociológica mais incisiva sobre a essência que marca os sistemas educacionais na modernidade, incluindo o moçambicano.

Este artigo insere-se em uma pesquisa mista de caráter eminentemente qualitativo com requintes quantitativos e contou com uma pesquisa bibliográfica e documental para a sua materialização, para além do método hermenêutico, que serviu de ferramenta crucial no âmbito da interpretação crítica das fontes escritas que corporizam o trabalho. Na perspectiva de Creswell (2007), a valência de métodos mistos no âmbito de estudos científicos repousa na sua potencialidade de vir a permitir ao pesquisador "a obtenção tanto de informações numéricas, como de informações de texto [...] de forma que o banco de dados final represente tanto informações quantitativas como qualitativas" (CRESWELL, 2007, p. 35) e que, segundo o autor, podem garantir uma melhor compreensão do problema da pesquisa.

No que se refere à sua estrutura, este estudo compreende quatro seções. A primeira delas é a introdução que, em geral, faz a apresentação das metamorfoses que permearam o SNE desde o período colonial até a atualidade, os objetivos, a pertinência, os referenciais teóricos e os procedimentos metodológicos que tornaram possível a consumação desta pesquisa. A segunda seção se debruça sobre a educação moçambicana com maior destaque para a configuração do Ensino Geral. A terceira seção discute analiticamente, com base nos fundamentos da sociologia da educação, os princípios, as implicações e os desafios que se colocam ao Regulamento de Avaliação adotado no ESG2 em Moçambique. E, finalmente, as considerações finais que, por sua vez, discorrem sobre os resultados decorrentes das análises documentais e das abordagens teóricas trazidas no corpus deste trabalho.

\section{A estrutura do atual Sistema Nacional de Educação - SNE de Moçambique}

A educação moçambicana se desdobra em três modalidades de ensino, nomeadamente: (i) o ensino pré-escolar/infantil; (ii) o ensino escolar, que compreende o ensino geral, técnico- 
profissional e o ensino superior; e, por fim, (iii) o ensino extra-escolar, que envolve as ações de alfabetização. Com relação ao SNE, cabe ainda ressaltar um elemento fundamental: o ensino geral é tido como o eixo central de todo o sistema de ensino, uma vez que os seus níveis e conteúdos constituem pontos de referência para a frequência das outras submodalidades do ensino escolar (MOÇAMBIQUE, 1992). O quadro 1 ilustra a estrutura (ou níveis) do atual Ensino Geral, no qual se insere o ESG2, foco dessa reflexão:

Quadro 1 - Estrutura do Ensino Geral vigente em Moçambique

\begin{tabular}{|l|c|c|}
\hline \multicolumn{1}{|c|}{ Níveis de ensino } & Classes/Séries & Faixa etária \\
\hline Ensino Pré-escolar/Infantil & -- & Abaixo dos 6 anos \\
\hline Ensino Primário do $1^{\circ} \mathrm{Grau}-\mathrm{EP} 1$ & $1^{\mathrm{a}}, 2^{\mathrm{a}}, 3^{\mathrm{a}}, 4^{\mathrm{a}} \mathrm{e} 5^{\mathrm{a}}$ classes & Dos 6 aos 10 anos \\
\hline $\begin{array}{l}\text { Ensino Primário do } 2^{\circ} \mathrm{Grau}-\mathrm{EP} 2 \\
\text { Ensino Secundário Geral do } 1^{\circ} \mathrm{Ciclo}-\end{array}$ & $6^{\mathrm{a}} \mathrm{e} 7^{\mathrm{a}}$ classes & Dos 11 aos 12 anos \\
\hline $\begin{array}{l}\text { ESG1 } \\
\text { ESGino Secundário Geral do } 2^{\circ} \text { Ciclo }-\end{array}$ & $8^{\mathrm{a}}, 9^{\mathrm{a}} \mathrm{e} 10^{\mathrm{a}}$ classes & Dos 13 aos 15 anos \\
\hline
\end{tabular}

Fonte: Quadro adaptado pelo autor com base na lei 6/92 de 6 de maio de 1992, referente ao Sistema Nacional de Educação - SNE (MOÇAMBIQUE, 1992).

O Ensino Pré-escolar (EPE) é definido como a modalidade de ensino destinada exclusivamente a crianças com idade inferior a seis anos como complemento da ação educativa exercida pelas famílias, com o objetivo de promover o desenvolvimento psíquico, físico e cognitivo das crianças. Em cumprimento do artigo $1^{\circ}$ da lei $n^{\circ} 6 / 92$ do $\mathrm{SNE}$ (MOÇAMBIQUE, 1992), que, entre outras inovações, liberalizou o setor da educação em Moçambique, o EPE é provido, em larga medida, pelas instituições particulares.

O Ensino Primário em Moçambique é sustentado integralmente pelo Estado e, a ele compete, no geral, a preparação das crianças para o seu acesso e integração ao Ensino Secundário Geral - ESG. Por sua vez, o ESG é público, embora haja a obrigatoriedade de pagamento de uma taxa anual de matrícula, pelos/as encarregados/as ou responsáveis dos/as educandos/as. Além de preparar os/as adolescentes e jovens para o Ensino Superior, constituem atribuições do ESG desenvolver no/a jovem "competências que o permitam participar ativamente na vida política, social e econômica do país" (MOÇAMBIQUE, 2007, p. 18).

Sob o ponto de vista das normativas que regem a educação moçambicana, impõe-se necessário conhecer algumas inovações introduzidas recentemente. $O$ parlamento Rev. Ed. Popular, Uberlândia, v. 20, n. 3, p. 103-121, set.-dez. 2021. 
moçambicano aprovou, em 2018, o novo SNE por meio da lei 18/2018 de 28 de dezembro ${ }^{3}$ (MOÇAMBIQUE, 2018b), que ainda espera por uma implementação efetiva. Em conformidade com a nova legislação educacional, a educação básica/obrigatória em Moçambique passará a ter uma extensão de 9 classes, sendo as 6 primeiras $\left(1^{\mathrm{a}}, 2^{\mathrm{a}}, 3^{\mathrm{a}}, 4^{\mathrm{a}}, 5^{\mathrm{a}}\right.$ e $\left.6^{a}\right)$ referentes ao Ensino Primário, e as três restantes ( $7^{\mathrm{a}}, 8^{\mathrm{a}}$ e $9^{\mathrm{a}}$ classe) ao ESG1. Em razão dessas metamorfoses, a configuração do novo ESG2 (foco deste trabalho) compreenderá três anos: $10^{\mathrm{a}}, 11^{\mathrm{a}}$ e a $12^{\mathrm{a}}$ classe (MOÇAMBIQUE, 2018b). Portanto, diferentemente do sistema educativo colonial que, em geral, sujeitou a grande maioria africana a frequentar o ensino primário rudimentar, desde a aprovação do primeiro SNE em 1983 (MOÇAMBIQUE, 1983) até a atualidade, todas as crianças moçambicanas e africanas residentes em Moçambique passaram a frequentar uma educação geral completa, constituída por um total de 12 anos de escolaridade, consumando-se, assim, pelo menos formalmente, um dos direitos fundamentais do homem (o direito à educação), decorrentes da Declaração Universal dos Direitos do Homem promulgada pelas Nações Unidas em 1948 (ONU, 1948). Todavia, de acordo com os estudos sociológicos da educação que embasam essa reflexão, o mero acesso à educação não significa automaticamente uma igualdade de oportunidades no interior dos sistemas educacionais (DUBET, 2003). Certamente, a educação moçambicana não é imune com relação a essa realidade, tendo em vista os princípios meritocráticos que parecem intrínsecos ao Regulamento de Avaliação do Ensino Primário, Ensino Secundário, Alfabetização e Educação de Adultos (MOÇAMBIQUE, 2018a) a ser abordado na próxima seção.

\section{Princípios, implicações e desafios que se impõem ao regulamento de avaliação adotado no ESG2 em Moçambique}

Os processos de avaliação no Ensino Secundário Geral (ESG), em Moçambique, e mais particularmente no ESG2, são regidos pelo Regulamento de Avaliação do Ensino Primário, Ensino Secundário, Alfabetização e Educação de Adultos (MOÇAMBIQUE, 2018a). Para além das diversas avaliações contínuas, sistemáticas e trimestrais realizadas ao longo do ano, em cada final do ano letivo, o/a aluno/a da $12^{\mathrm{a}}$ classe é submetido/a a avaliações finais, vulgarmente denominadas de exames, elaboradas e sistematizadas pelo Ministério de

\footnotetext{
${ }^{3}$ À luz da lei no 18/2018 (MOÇAMBIQUE, 2018b), que alarga a escolaridade obrigatória até a 9a classe, as crianças e adolescentes que frequentam a $8^{a}$ e $9^{a}$ classe estão isentos de pagar a taxa de matrícula. Disponível em: cf. http://www.portaldogoverno.gov.mz/por/Imprensa/Noticias/2019-governo-Isenta-Taxas-de-Matriculas-daprimeira-a-nona-classe. Acesso em: 20 dez. 2019.
} 
Educação e Desenvolvimento Humano (MINEDH) a partir das propostas recolhidas ao nível das províncias ${ }^{4}$. Segundo a mesma fonte, o/a aluno/a da $12^{\text {a }}$ classe deve prestar um total de sete exames nas disciplinas referentes à sua área curricular, incluindo as disciplinas gerais ou do tronco comum ${ }^{5}$. Nos termos desse Regulamento, são três os componentes subjacentes ao processo de avaliação final na $12^{\mathrm{a}}$ classe, designadamente: a exclusão, a admissão e a aprovação dos exames.

(i) Exclusão: perde o direito de realizar exame(s) de uma ou mais disciplinas, o(a) aluno(a) que tenha obtido uma média de frequência/anual abaixo de 10 valores, em uma escala de valores de 0 a 20. A exclusão pode ser parcial, ou global se o(a) aluno(a) tiver obtido uma média anual abaixo de $10 \mathrm{em}$ todas as disciplinas;

(ii) Admissão: somente tem acesso aos exames, o(a) aluno(a) que tenha obtido uma média igual ou superior a 10 em uma ou mais disciplinas. A exclusão, a admissão ou o acesso aos exames no ESG2 pode ser parcial ou integral se, por exemplo, o(a) aluno(a) tiver obtido uma média anual igual ou superior a 10 nas sete disciplinas sujeitas aos exames;

(iii) Aprovação: só é atribuída ao(à) aluno(a) que tenha obtido uma nota mínima igual ou superior a 9 em todos os exames realizados $^{6}$. (MOÇAMBIQUE, 2018a).

Sob o ângulo da sociologia da educação, as disposições que formalmente condicionam a aprovação dos/as alunos/as nos sistemas educacionais modernos (sem excetuar o moçambicano) se inserem na lógica do que Bourdieu (1998b) chamaria de ritos de instituição ou de consagração social. Na perspectiva do autor, denominam-se ritos de instituição/consagração social os atos que ocorrem no campo escolar e que se consubstanciam com a distribuição seletiva dos diplomas escolares. Em todas as esferas sociais, e, particularmente no campo educacional, tais rituais produzem toda uma série de condições

\footnotetext{
${ }^{4}$ Províncias são equivalentes aos estados no Brasil.

${ }^{5}$ Os alunos que frequentam a área de Comunicação e Ciências Sociais são submetidos aos exames de História, Geografia, Francês (disciplinas específicas da área); e Português, Inglês, Filosofia e Matemática (disciplinas gerais), totalizando sete disciplinas. Na área de Matemática e Ciências Naturais, realizam-se exames nas disciplinas de: Biologia, Química, Física (disciplinas específicas); e Filosofia, Inglês, Português, Matemática (disciplinas gerais). E, por fim, na área de Artes Visuais e Cênicas, realizam-se exames nas disciplinas de: Desenho e Geometria Descritiva, Física e Química (disciplinas específicas); Matemática, Filosofia, Inglês e Português (disciplinas gerais).

${ }^{6}$ Nota mínima é o rendimento obrigatório que cada aluno deverá obter em cada exame. Por exemplo, se determinado/a aluno/a tiver sido admitido/a aos exames em todas as disciplinas, ele/ela deverá alcançar a nota mínima em cada uma delas, como condição indispensável para a sua aprovação de classe, de forma integral, ou então, parcialmente, se porventura tiver conseguido a nota mínima em apenas algumas disciplinas (MOÇAMBIQUE, 2018a).
} 
favoráveis à distinção e/ou à diferenciação social entre os/as alunos/as, ou seja, uma estratificação entre os/as aprovados/as e os/as reprovados/as. Para a demonstração da linha abissal/divisória decorrente dos processos de instituição/consagração social que marcam as sociedades modernas, o autor recorre ao exemplo da circuncisão masculina:

na realidade, o mais importante, e que em geral passa despercebido, é a divisão que essa linha opera entre o conjunto daqueles passíveis de serem circuncidados, os meninos, os homens, crianças ou adultos, daqueles que não o são, a saber, as meninas e as mulheres. Existe, portanto, um conjunto oculto em relação ao qual se define o grupo instituído. O principal efeito do rito é o que passa quase sempre completamente despercebido: ao tratar diferentemente os homens e as mulheres, o rito consagra a diferença, ele a institui, instituindo ao mesmo tempo o homem enquanto homem, isto é, circuncidado, e a mulher enquanto mulher, isto é, não passível dessa operação ritual. (BOURDIEU, 1998b, p. 98).

A partir dos argumentos de Bourdieu (1998b), torna-se evidente o efeito distintivo e abissal decorrente das cerimônias de consagração social promovidas pelas sociedades modernas. Enquanto a circuncisão masculina separa os homens dos não homens (mulheres), na esfera educacional, a consagração social separa os/as alunos/as aprovados/as dos/as reprovados/as de uma forma irreconciliável. Na mesma linha discursiva, Valle (2015a), intérprete e estudiosa do pensamento de Pierre Bourdieu (1930-2002), assinala que a consagração social é um ato que se consubstancia basicamente com a atribuição de títulos escolares aos/às alunos/as aprovados/as, o que provoca, paralela e sistematicamente, um conjunto de efeitos socialmente estratificantes ao "constituir as pessoas como diferentes, produzindo nelas diferenças permanentes e indeléveis, sejam externas, como os distintivos, ou

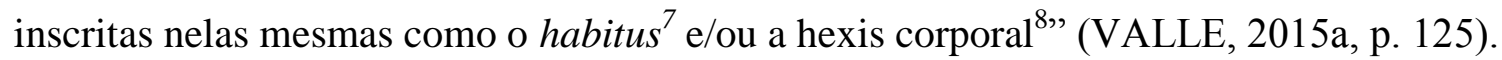

Retomando as discussões sobre a realidade moçambicana, cabe agora referenciar outro princípio básico e intrínseco aos processos nacionais de avaliação no ESG2. Na 12a classe, os exames finais ocorrem em duas épocas e o/a aluno/a só pode aceder aos exames da $2^{\mathrm{a}}$ época, se ele/ela tiver reprovado, no máximo, em três disciplinas na $1^{\mathrm{a}}$ época. $\mathrm{O}$ incumprimento dessa disposição pelo/a aluno/a resvala automaticamente para a sua reprovação, devendo,

\footnotetext{
${ }^{7}$ O Habitus refere-se às disposições (sociais e psicológicas) estruturantes e estruturadas que determinam as nossas ações quotidianas, as nossas práticas e as nossas representações (NOGUEIRA, M.; NOGUEIRA, C., 2009).

${ }^{8}$ A hexis corporal se manifesta na forma como as pessoas se comportam sob o ponto de vista físico, ou nos seus gostos com relação a forma de estar, por exemplo, a indumentária, a etiqueta, os cuidados com o corpo. Isso culmina com a apologia da proporcionalidade e/ou correspondência entre o psíquico e o corporal (VALLE, 2015a).
} 
dessa maneira, rematricular-se no próximo ano letivo. Além disso, no ESG1 (8 ${ }^{\mathrm{a}}, 9^{\mathrm{a}}$ e $10^{\mathrm{a}}$ classe), o/a aluno/a pode reprovar, no máximo, duas vezes, e no ESG2 (11 a e $12^{\mathrm{a}}$ classe), foco deste estudo, apenas 1 vez (MOÇAMBIQUE, 2018a). Assim sendo, o(a) aluno(a) que extrapola as reprovações recomendadas pelo regulamento de avaliação perde o direito à matrícula, caindo inevitavelmente numa exclusão social. Paradoxalmente, segundo alguns documentos norteadores da educação moçambicana, tal medida exerce um papel decisivo para o sucesso escolar no interior das escolas moçambicanas. Esse entendimento consta da Estratégia do Ensino Secundário 2009-2015 (MOÇAMBIQUE, 2009) segundo a qual:

como forma de promover o sucesso escolar dos alunos e assegurar que eles concluam o ciclo em tempo oportuno, de modo a permitir maior fluxo dos alunos entre os ciclos de aprendizagem, aos alunos das escolas públicas só será permitida, excepcionalmente, uma reprovação em cada ciclo. (MOÇAMBIQUE, 2009, p. 61-62).

Essencialmente, a problemática do insucesso escolar transcende a simples determinação do tempo limite de permanência de alunos/as dentro do sistema escolar. Tratase de uma questão que deveria passar pela mitigação das desigualdades que, no geral, marcam intensamente os/as alunos/as durante o seu percurso de escolarização, e que, ao mesmo tempo, podem exercer efeitos parcialmente estratificantes no que se refere ao seu enquadramento social e profissional, ou então, com relação às posições e hierarquias sociais no seio das sociedades modernas (BOURDIEU; CHAMPAGNE, 1998).

No prefácio de Os herdeiros, de Bourdieu e Passeron (2018), Valle (2018) coloca argumentos elucidativos inerentes à lógica meritocrática e reprodutivista intrínseca aos sistemas modernos de ensino e avaliação:

os sistemas de ensino reproduzem as desigualdades sociais por meio do estabelecimento de uma relação estreita entre intelectuais (professores), educação e classes privilegiadas. Suas análises vão mostrar que a função de perpetuação das desigualdades em face da cultura predomina nos processos de escolarização, sendo levada a efeito por recursos pedagógicos (e de avaliação) que transformam privilégios socialmente condicionados, em méritos, dons e talentos individuais, legitimando-os. (VALLE, 2018, p. 9).

As teses de Valle (2018) desmascaram a face oculta que tem vindo a permear os sistemas de ensino modernos. Efetivamente, os sistemas de ensino produzem um conjunto de mecanismos consensuais e apropriados no que se refere à criação de hierarquias e desigualdades sociais entre os/as alunos/as, naturalizando, para o efeito, uma gama de 
dificuldades decorrentes da situação social precária e desfavorável das classes populares. À luz do paradigma meritocrático hiperindividualista (VALLE, 2010), os/as alunos/as provenientes dessas classes e, muitas vezes, detentores/as de um insignificante/baixo capital cultural $^{9}$, são classificados/as como sendo desprovidos/as de disposições psíquicas no domínio das questões epistemológicas e, em contrapartida, os/as aprovados/as nos exames são nomeados/as como talentosos/as.

De fato, a gênese das desigualdades no meio escolar decorre da mobilização pelas instituições de ensino, de um conjunto de códigos culturais próprios de uma socialização primária, e que colocam inevitavelmente as crianças das classes populares em uma posição desvantajosa em relação às provenientes de famílias socialmente mais favorecidas. Tal fenômeno evidencia a existência de uma autêntica conivência e/ou proximidade do herdeiro ${ }^{10}$ com o mundo científico-escolar, considerando que, no âmbito de uma educação formal secundária, os processos epistêmicos inerentes, tanto à produção do conhecimento quanto à sua transmissão, operam-se com base na sua linguagem habitual (VALLE, 2015b).

Maria Nogueira e Cláudio Nogueira (2009), também intérpretes e estudiosos do pensamento de Bourdieu (1930-2002) e de Passeron (1930-), assinalam que:

o indivíduo que domina, por exemplo, o padrão culto da língua, aquele reconhecido como legítimo pelas infâncias às quais foi socialmente atribuído o direito e o dever de avaliar e classificar as formas de linguagem; o domínio da língua culta funciona como uma moeda, um capital, que propicia a quem o possui uma série de recompensas, seja no sistema escolar, seja no mercado de trabalho, seja até mesmo no mercado matrimonial; dentro da literatura, o conhecimento sobre autores, estilos e obras e, sobretudo, a capacidade de produzir obras reconhecidas como de alta qualidade constituem uma forma de capital (capital literário) que propicia, a quem o detêm, um poder de influência sobre o campo em questão. (NOGUEIRA, M.; NOGUEIRA, C., 2009, p. 35).

À semelhança das perspectivas de Bourdieu (1998b) e Valle (2015b), de acordo com Maria Nogueira e Cláudio Nogueira (2009), no contexto educacional, as desigualdades sociais resultam da ostentação exclusiva dos bens culturais, científicos e artísticos (capital cultural), num grupo (a classe dominante) em prejuízo do outro, o menos favorecido e que representa as

\footnotetext{
${ }^{9}$ Dá-se o nome de capital cultural ao conjunto de saberes de ordem artística, cultural, literária e científica, normalmente detidos por alunos provenientes de famílias cultas (BOURDIEU, 1998b; NOGUEIRA, M.; NOGUEIRA, C., 2009; VALLE, 2015b).

${ }^{10} \mathrm{O}$ termo herdeiro é atribuído aos filhos das famílias cultas, e, por isso, dotados de bases intelectuais em todas as dimensões, nomeadamente: o saber-fazer e o saber-pensar/dizer exigidos, preferível e incondicionalmente, pelos sistemas de ensino (BOURDIEU; PASSERON, 2014 apud VALLE et al., 2015b).
} 
classes populares, cobrando dos/as alunos/as um conjunto de atitudes, comportamentos e habilidades linguísticas que são, em sua maioria, de domínio das crianças pertencentes às classes dominantes.

Os dados documentais denotam que, a educação moçambicana não constitui nenhuma exceção em relação ao chamado paradigma meritocrático hiperindividualista discutido por Valle (2010), uma vez que à luz do Relatório do Desempenho do Setor da Educação referente ao letivo de 2016, apresentado na $18^{a}$ Reunião Anual de Revisão do Ministério de Educação e Desenvolvimento Humano (MOÇAMBIQUE, 2017), entre os fatores que concorrem para a prevalência do baixo rendimento escolar no ESG2, destaca-se a "falta de aplicação e interesse dos alunos [...], acompanhamento irregular dos pais e encarregados(as) de educação" (MOÇAMBIQUE, 2017, p. 10). Analiticamente, tal entendimento decorre de uma responsabilidade verticalizada que permeia as políticas de avaliação escolar na atualidade que, em geral, "se esquecem que não basta o dado do desempenho do aluno [...], em um teste ou questionário e seus fatores associados, é preciso que o dado seja reconhecido como pertencendo à escola; medir propicia um dado, mas medir não é avaliar" (FREITAS et al., 2009, p. 48).

A responsabilização exclusiva que se atribui aos/às alunos/as e suas famílias pelo baixo aproveitamento escolar, negligencia, de forma parcial, a situação socioeconômica e educacional desequilibrada e prevalecente na sociedade moçambicana, conforme o Instituto Nacional de Estatística - INE (MOÇAMBIQUE, 2019, p. 85). Na mesma ótica, o Plano Estratégico da Educação 2020-2029 reconhece as assimetrias regionais como um elemento relevante que deveria ser levado em conta no processo de escolarização em Moçambique: "a distância casa-escola continua muito grande, chegando a ultrapassar os 40 quilômetros, e os custos para a frequência do Ensino Secundário - livros, transporte, matrícula e inscrição são insustentáveis para a maioria das famílias” (MOÇAMBIQUE, 2020, p. 85).

As assimetrias sociais exercem um papel determinante para a aquisição de um capital cultural $^{11}$ diferenciado entre as crianças, e que influencia fortemente o (in)sucesso escolar no interior da escola moderna (BOURDIEU, 1998b; NOGUEIRA, M.; NOGUEIRA, C., 2009; VALLE, 2015b).

Com relação ao capital cultural/linguístico, atualmente, além da taxa do analfabetismo que se situa em 39\% (MOÇAMBIQUE, 2019), a Língua Portuguesa, meio privilegiado pelo

\footnotetext{
${ }^{11}$ Dá-se o nome de capital cultural, ao conjunto de saberes de ordem artística, cultural, literária e científica, normalmente detidos por alunos provenientes de famílias cultas (BOURDIEU, 1998b; NOGUEIRA, M.; NOGUEIRA, C., 2009; VALLE, 2015b).
} 
qual se media o processo educativo nas escolas secundárias em Moçambique, é falada por cerca de 40\%12 da população moçambicana. Como resultado, segundo o Plano Curricular do Ensino Secundário Geral - PCESG (MOÇAMBIQUE, 2007), o fraco domínio da Língua Portuguesa pela grande maioria de alunos/as tem vindo a impactar negativamente nos resultados das provas e exames ao nível do ESG. Sobre essa problemática, a pesquisa de Chimbutane (2015) refere que várias publicações têm vindo a denunciar, de forma contundente, os efeitos segregacionistas decorrentes da posição privilegiada que as ex-línguas coloniais (ocidentais) assumem no contexto das políticas educativas ao nível do continente africano. Devido a sua ancoragem nas antigas línguas coloniais, as políticas educativas/curriculares, em diversas nações africanas (sem excetuar Moçambique), têm vindo a gerar resultados socialmente desanimadores. Ao invés de criarem uma inclusão social/escolar, tais políticas colaboram para a agudização das desigualdades sociais entre os alunos na África, a favor de uma minoria educada e socioeconomicamente bem posicionada. Dito de outra forma, o embasamento das políticas educativas/curriculares nas línguas ocidentais, hoje oficiais na África pós-independente, tem vindo a exercer uma ação significativamente perversa no processo de escolarização para a maioria das camadas populares (ALEXANDER, 1999; ALIDOU; JUNG, 2001; HEUGH, 2008 apud CHIMBUTANE, 2015).

Ainda que sejam de diferentes autores, as perspectivas teóricas discutidas até aqui assinalam, sincronicamente, que prevalece na escola moderna os chamados "excluídos do interior" ${ }^{\text {"13 }}$ e isso evidencia que a conquista do direito à educação nem sempre foi sinônimo de uma plena democratização educacional (BOURDIEU; CHAMPAGNE, 1998). No Brasil, por exemplo, um das pesquisas realizadas em 2009 esclarece que, enquanto desde 1988 se celebra a conquista jurídica do direito à educação, persistem atualmente altos níveis de "baixo desempenho escolar, abandono precoce, exclusão de grandes contingentes de educandos, segregação escolar no interior dos próprios sistemas de ensino" (VALLE; RUSCHEL, 2009, p. 180).

A par dos resultados da pesquisa realizada no Brasil (VALLE; RUSCHEL, 2009), 46 anos após a proclamação da independência e do direito à educação para todos/as, uma das

\footnotetext{
12 Disponível em: https://www.dn.pt/portugal/interior/portugues-cada-vez-mais-falado-nas-zonas-urbanas-democambique-1259460.html. Acesso em: maio de 2019.

${ }^{13}$ À luz de Bourdieu e Champagne (1998), a categoria dos excluídos do interior tem a ver com a grande maioria de alunos/as das classes desfavorecidas que, mesmo tendo acesso à educação, têm estado a enfrentar sistematicamente enormes dificuldades e desigualdades sociais por dentro dos sistemas de ensino.
} 
questões preocupantes que parece permear a educação moçambicana, e, especificamente, o ESG2, são os indícios de uma educação meritocrática decorrentes do atual Regulamento de Avaliação vigente (MOÇAMBIQUE, 2018a), razão pela qual os índices de evasão, repetência e, sobretudo, de reprovação escolar no ESG2, em Moçambique, têm-se mostrado relativamente altos, conforme a tabela 1 .

Tabela 1 - Taxas de reprovação no ESG2 (12 classe)

\begin{tabular}{c|c|c|c}
\hline $\mathbf{2 0 1 2}$ & $\mathbf{2 0 1 4}$ & $\mathbf{2 0 1 6}$ & $\mathbf{2 0 1 8}$ \\
\hline $32 \%$ & $25 \%$ & $27,3 \%$ & $22,6 \%$ \\
\hline
\end{tabular}

Fonte: Adaptada pelo autor com base no Plano Estratégico da Educação 2020-2029 (MOÇAMBIQUE, 2020).

Na perspectiva do Plano Estratégico da Educação 2020-2029 (MOÇAMBIQUE, 2020, p. 85), as reprovações "constituem um grande desperdício de recursos no Sistema de Ensino em Moçambique e a sua redução no Ensino Secundário constitui uma das prioridades do setor". Como resultado, em 2017, apenas 29\% dos alunos concluíram o ESG1 e 13\% o ESG2.

Mazula (2018) afirma que os baixos rendimentos escolares que têm sido persistentes no Ensino Secundário Geral em Moçambique prendem-se com o modelo curricular que embasa os processos de avaliação. Os exames nacionais, conforme sublinha o autor, têm vindo a ser elaborados tomando como alicerce o currículo ideal (oficial) em prejuízo do currículo real, decorrente da dialética docente-discente em sala de aula. Ou seja, "a política de avaliação surge como algo imposto de cima para baixo [...], há disparidades entre a avaliação que o professor faz ao longo do ano e o exame nacional" (DUARTE, 2018, p. 42), fator que acaba por influenciar as reprovações escolares e/ou o insucesso escolar dentro do sistema educacional em Moçambique.

\section{Considerações finais}

Os pressupostos da sociologia da educação, mobilizados para a fundamentação dos argumentos arrolados no corpus deste trabalho, destacam, no geral, o agravamento das desigualdades sociais no âmbito educacional, pondo, dessa maneira, em xeque, todo o projeto sobre a democratização escolar tão intensamente propalado pelos Estados modernos (liberais), sobretudo a partir dos princípios emanados pela Revolução Francesa. 
No contexto de Moçambique, tal discurso remonta, em primeiro lugar, a lei $n^{\circ} 4 / 83$ de 23 de março, que regulou o $1^{\circ}$ Sistema Nacional de Educação (MOÇAMBIQUE, 1983). Posteriormente, a democratização educacional foi e é reafirmada pela primeira Constituição multipartidária do país, aprovada em 1990 e atualizada em 2004 (MOÇAMBIQUE, 2004), e pela lei nº 18/2018 do novo SNE (MOÇAMBIQUE, 2018b, p. 19), que impõe no seu artigo $3^{\circ}$ “a promoção da democratização do ensino, garantido o direito a uma justa e efetiva igualdade de oportunidades no acesso e sucesso escolar dos cidadãos".

Contudo, objetivamente, a partir das perspectivas teóricas que ancoram a presente discussão, pode-se depreender que os princípios que emanam do Regulamento de Avaliação (MOÇAMBIQUE, 2018a) e que condicionam o acesso aos exames da $1^{\mathrm{a}}$ e $2^{\mathrm{a}}$ época na $12^{\mathrm{a}}$ classe, e as taxas relativamente altas de evasão, sobretudo, de repetência e reprovação escolares (MOÇAMBIQUE, 2020), são elementos fortes e potenciais que consubstanciam o desenvolvimento de uma educação meritocrática no Ensino Secundário Geral em Moçambique. Aliado a isso, a nota mínima instituída como conditio sine qua non para a aprovação em cada exame na $12^{\mathrm{a}}$ classe e a determinação do tempo limite de permanência dos(as) alunos(as) no interior do sistema de ensino podem ser tomados sociologicamente como indicadores inequívocos de uma abordagem excludente que continua a dominar a educação moçambicana, 38 anos após a aprovação da lei 4/83 que regulou o primeiro SNE autônomo (MOÇAMBIQUE, 1983).

Como nos lembra Golias (1993), o programa de escolarização obrigatória e universal, aprovado pelo Governo de Moçambique em 1975, tornou-se, posteriormente, em uma hipocrisia generalizada, uma vez que, efetivamente, além de reprovações em massa, milhares de crianças e adolescentes continuam sem acesso à escola e poucos é que têm vindo a lograr sucesso no contexto escolar. No período pós-independência, o Estado moçambicano, movido pelos ideais socialistas, procurou promover uma política de educação para todos. Entretanto, na prática, tal projeto resvalou para uma qualidade de educação para poucos, na medida em que, longe de cumprir com o seu propósito de criar oportunidades de aprovação iguais e justas para todos/as, o paradigma de avaliações nacionais vigente no Ensino Primário e Secundário acabou por acentuar as desigualdades sociais no interior do sistema educacional (CASTIANO; NGOENHA, 2013).

Em decorrência disso, de acordo com Basílio (2017), a materialização do propalado princípio de igualdade de oportunidades na esfera educacional não se restringe à massificação do acesso. É fundamental, sim, que se leve a cabo um projeto educacional que garanta a 
manutenção dos alunos. Tal ação, afirma o autor, não pode ser vista como sinônimo de retenção e/ou reprovação de alunos, mas como criação de mecanismos e condições que os levem a concluir com sucesso os seus níveis de escolaridade.

Esse quadro teórico deveria reforçar a possibilidade/necessidade, por parte das autoridades que dirigem a educação em Moçambique, de operar um conjunto de transformações que favoreçam a revisão dos princípios meritocrático-excludentes decorrentes dos processos de avaliação ora analisados, e, consequentemente, a promoção de políticas educativas e curriculares mais adequadas ao capital cultural/linguístico que marca a grande maioria de alunos/as e/ou às condições sociais intensamente assimétricas que permeiam as famílias moçambicanas, conforme o INE (MOÇAMBIQUE, 2019).

Portanto, a concretização plena do desiderato de uma escola justa na era contemporânea e, em particular, do lema "por uma educação inclusiva, patriótica e de qualidade", defendido pelo Ministério de Educação e Desenvolvimento Humano de Moçambique - MINEDH (MOÇAMBIQUE, 2020), impõe vários desafios às autoridades educativas nacionais, não apenas no que se refere à oferta, como também, e, sobretudo, no que diz respeito à salvaguarda da desejável dimensão de inclusão dentro do próprio sistema de ensino. Ademais, o mérito individual que parece fundamentar os princípios de avaliação no ESG2 em Moçambique, e, extensivamente, os sistemas educacionais atuais, somente pode fazer sentido se os agentes sociais empreenderem todo e qualquer tipo de competição a partir de condições integralmente igualitárias, ou seja, “o princípio de igualdade de oportunidades tem um antes, e um depois: antes de ingressar na competição, todas as condições devem ser igualadas, todos os ponteiros devem ser zerados" (ROEMER, 2000 apud VALLE, 2010, p. 37). Uma vez criadas as condições para uma competição mais justa cada um deverá assumir sua responsabilidade no processo educacional, ressalta Roemer (2000 apud VALLE, 2010).

Por outro lado, a mudança de paradigma no que diz respeito aos princípios que regem os processos de avaliação na $12^{\mathrm{a}}$ classe, passaria necessariamente por um maior engajamento em uma avaliação formativa capaz de superar os esquemas meritocráticos, próprios de uma aprendizagem por competências, imposta oficialmente pelo Plano Curricular do Ensino Secundário Geral - PCESG (MOÇAMBIQUE, 2007), e difundida amplamente a partir das entidades internacionais, tais como: a Organização para a Cooperação e Desenvolvimento Econômico - OCDE, Banco Mundial - BM e a Agência das Nações Unidas para a Educação, Ciência e Cultura - UNESCO, da qual Moçambique é membro desde 1975. O modelo de avaliação formativa exerceria uma ação de preponderância na humanização dos processos 
epistêmico-didáticos ligados à transmissão e produção de conhecimentos em sala de aula. A relevância de uma avaliação formativa está na sua potencialidade de vir a garantir a identificação dos "sucessos e problemas de percurso, permitindo ao professor ajudar a superálos" (DUARTE, 2018, p. 38).

Enfim, trata-se de uma avaliação mais solidária, flexível e aberta, que permite ao professor acompanhar, de maneira sistemática e holística, os altos e baixos, os maus e bons momentos, vivenciados por cada aluno durante toda a cadeia de ensino e aprendizagem. Em relação a isso, as contribuições de Paulo Freire (1921-1997) também se mostram cruciais. Valendo-se da obra de Freire (2017), faz-se necessário o empreendimento de uma "pedagogia do oprimido", fundada no diálogo intersubjetivo e, por isso, capaz de desconstruir os esquemas oprimentes, antidemocráticos e individualistas, intrínsecos aos sistemas de ensino na atualidade, sem excetuar o moçambicano.

Mais do que se limitar à relação entre professor e alunos/as em sala de aulas, em Moçambique, os presupostos da "pedagogia do oprimido", propostos por Freire (2017), (re)aproximariam cada vez mais as instituições educacionais em todos os níveis, designadamente, o MINEDH, as Direções Provinciais da Educação (equivalentes às Secretarias Estaduais de Educação no Brasil), as Direções Distritais da Educação (equivalentes às Secretarias Municipais de Educação), as escolas e as comunidades locais, o que, por sua vez, seria relevante para tornar o processo de concepção/revisão das políticas públicas educacionais menos tecnicista rumo ao desenvolvimento de uma plena educação inclusiva e democrática.

Todavia, pegando de empréstimo as palavras de Popper (1980), essa discussão é uma proposição de índole falibilista, cujo estatuto epistemológico dependerá sempre da realização de novos estudos científicos, tal como sugerem as autoridades educativas nacionais (MOÇAMBIQUE, 2020) ao salientarem que o empreendimento de mais pesquisas acadêmicas transforma-se em componente indispensável para uma apreensão cada vez profunda dos reais fatores que têm estado a influenciar a prevalência de altas taxas de reprovações e de evasão escolar, em particular, nos estabelecimentos do Ensino Secundário em Moçambique.

\section{Referências}

BASÍLIO, G. Fundamentação epistemológica do currículo local. In: CAPECE, J. A.; BASÍLIO, G. (org.). O currículo local: teoria e prática. Maputo: Educar-UP, 2017. p. 17-49. 
BASÍLIO, G. O Estado e a escola na construção da identidade política moçambicana. 2010. Tese (Doutorado em Educação) - Pontifícia Universidade Católica de São Paulo, São Paulo, 2010. Disponível em:

https://tede2.pucsp.br/bitstream/handle/10227/1/Guilherme\%20Basilio.pdf. Acesso em: $1^{\text {o }}$ jan. 2021.

BOURDIEU, P. A economia das trocas linguísticas: o que falar quer dizer. São Paulo: EDUSP, 1998a.

BOURDIEU, P. Os herdeiros: os estudantes e a cultura. 2. ed. Florianópolis: EDUFSC, 2018.

BOURDIEU, P. Os três estados do capital cultural. In: NOGUEIRA, M. A.; CATANI, A. Escritos de educação. Petrópolis, RJ: Vozes, 1998b. p. 71-79.

BOURDIEU, P.; CHAMPAGNE, P. Os excluídos do interior. In: NOGUEIRA, M. A.;

CATANI, A. Pierre Bourdieu: escritos de educação. 8. ed. Petrópolis, RJ: Vozes, 1998. p. 217-227.

BOURDIEU, P.; PASSERON, J. C. A reprodução: elementos para uma teoria do sistema de ensino. Petrópolis, RJ: Vozes, 2008.

CASTIANO, J. P.; NGOENHA, S. E. A longa marcha duma educação para todos em Moçambique. 3. ed. Maputo: Publifix, 2013.

CHIMBUTANE, F. Línguas e educação em Moçambique: uma perspectiva sócio-histórica. In: GONÇALVES, P.; CHIMBUTANE, F. (org.). Multilinguismo e multiculturalismo em Moçambique: em direção a uma corrente entre discurso e prática. Maputo: Alcance, 2015. p. $35-75$.

CRESWELL. J. W. Projeto de pesquisa: métodos qualitativo, quantitativo e misto. 2. ed. Porto Alegre: Artmed, 2007.

DUARTE, S. M. A avaliação por ciclos de aprendizagem no Ensino Básico em Moçambique: entre tensões e desafios. Práxis Educativa, Ponta Grossa, v. 13, n. 1, p. 33-47, jan./fev. 2018. Doi: 10.5212/PraxEduc.v.13i1.0002. Disponível em:

http://www.revistas2.uepg.br/index.php/praxiseducativa. Acesso em: 27 set. 2020.

DUBET, F. Desigualdades multiplicadas. Rio Grande do Sul: Unijuí, 2003.

FREIRE, P. Pedagogia do oprimido. 64. ed. Rio de Janeiro: Paz \& Terra, 2017.

FREITAS, L. C. de et al. Avaliação educacional: caminhando pela contramão. Petrópolis, RJ: Vozes, 2009.

GASPERINI, L. Moçambique: educação e desenvolvimento rural. Roma: Edizioni Lavoro, 1989. 
GOLIAS, M. Sistemas de ensino em Moçambique: passado e presente. Maputo: Editora Escolar, 1993.

MAZULA, B. A complexidade de ser professor em Moçambique e seus desafios. Maputo: Plural Editores, 2018.

MOÇAMBIQUE. [Constituição 2004)]. Constituição da República de Moçambique.

Disponível em: http://cedis.fd.unl.pt/wp-content/uploads/2016/01/CONST-2004.pdf. Acesso em: $1^{\circ}$ out. 2020.

MOÇAMBIQUE. Boletim da República. Lei no 18, de 28 de dezembro de 2018. I Série, n. 254. Reajusta o Quadro Geral do Sistema Educativo. Maputo: Imprensa Nacional, 2018b.

MOÇAMBIQUE. Boletim da República. Lei n 4, de 23 de março de 1983. Aprova e Lei do Sistema Nacional de Educação e define os principíos fundamentais na sua apliação. Série, n. 12. Aprova a Lei do Sistema Nacional de Educação. Maputo: Imprensa Nacional, 1983.

MOÇAMBIQUE. Boletim da República. Lei no 6, de 6 de maio de 1992. Reajusta o quadro geral do Sistema Nacional de Educação (SNE) e adequa as disposições nele contidas. I Série, n. 19. Maputo: Imprensa Nacional, 1992.

MOÇAMBIQUE. Instituto Nacional de Estatística. Resultados definitivos.

Maputo/Moçambique, 2019. Disponível em: www.ine.gov.mz. Acesso em: 20 ago. 2019.

MOÇAMBIQUE. Ministério da Educação e Desenvolvimento Humano. Plano estratégico de educação/18a Reunião Anual de Revisão: Desempenho do setor da educação/relatório 2016. Maputo, 2017.

MOÇAMBIQUE. Ministério da Educação e Desenvolvimento Humano. Plano estratégico de educação 2020-2029: por uma educação inclusiva, patriótica e de qualidade. Maputo, 2020. Disponível em: https://planipolis.iiep.unesco.org/sites/planipolis/files/ressources/2020-22mozambique-esp.pdf. Acesso em: 30 set. 2020.

MOÇAMBIQUE. Ministério da Educação e Desenvolvimento Humano. Regulamento de avaliação do ensino primário, ensino secundário geral e alfabetização e educação de adultos. Maputo, 2018a. Disponível em:

http://www.mined.gov.mz/Documents/REG.Avaliac\%CC\%A7a\%CC\%83o\%20(003).pdf. Acesso em: $1^{\circ}$ jan. 2021.

MOÇAMBIQUE. Ministério da Educação. Estratégia do ensino secundário 2009-2015. Maputo, 2009. Disponível em:

http://www.mined.gov.mz/Legislacao/Documents/Estrat\%C3\%A9gia\%20do\%20Ensino\%20S ecund\%C3\%A1rio\%20Geral\%202009\%20-\%2020015.pdf. Acesso em: 1 jan. 2019.

MOÇAMBIQUE. Ministério da Educação ${ }^{14}$. Plano curricular do ensino secundário geral. Maputo: INDE, 2007. Disponível em: http://www.eln.co.mz/wpcontent/uploads/2015/04/programa.pdf. Acesso em: 20 jul. 2021 ${ }^{14}$ Com a ascensão ao poder do atual governo de Moçambique, como resultado das eleições legislativas e
presidenciais de 2014, o então Ministério da Educação (MINED) foi transformado em Ministério da Educação e
Rev. Ed. Popular, Uberlândia, v. 20, n. 3, p. 103-121, set.-dez. 2021. 
NOGUEIRA, M. A.; NOGUEIRA, C. M. M. Bourdieu e a educação. 3. ed. Belo Horizonte: Autêntica, 2009.

ONU. Declaração Universal dos Direitos do Homem. 1948. Disponível em:

http://www.educadores.diaadia.pr.gov.br/modules/conteudo/conteudo.php? conteudo=789.

Curitiba, Acesso em: 10 jan. 2018.

POPPER, K. Conjecturas e refutações. Brasília: Editora UnB, 1980.

VALLE, I. R.; RUSCHEL, E. A meritocracia na política educacional brasileira (1930-2000).

Revista Portuguesa de Educação, Braga, v. 22, n. 1, p. 179-206, 2009. Doi:

10.21814/rpe.13957. Disponível em:

http://www.scielo.pt/scielo.php?script=sci_arttext\&pid=S0871 -

91872009000100008\&lang=pt. Acesso em: $1^{\circ}$ ago. 2021.

VALLE, I. R. Justiça na escola: das desigualdades justas à igualdade sem adjetivos. In:

VALLE, I. R.; SILVA, V. L. G. da; DAROS, M. das D. (org.). Educação escolar: justiça social. Florianópolis: NUP, 2010. p. 19-49.

VALLE, I. R. Uma escola justa contra o sistema de multiplicação das desigualdades sociais. Educar em Revista, Curitiba, n. 48, p. 289-3017, jun. 2013b. Doi: 10.1590/S010440602013000200017. Disponível em: http://www.scielo.br/pdf/er/n48/n48a17.pdf. Acesso em: 20 jun. 2018.

VALLE, I. R. Da meritocracia escolar financiada pela família à meritocracia escolar promovida pelo estado: a igualdade de oportunidades progride a passo. Revista Tempos e Espaços em Educação, Sergipe, v. 8, n. 15, p. 121-131, jan./abr. 2015a. Doi: 10.20952/revtee.v8i15.3696. Disponível em:

https://seer.ufs.br/index.php/revtee/article/view/3696. Acesso em: 1 ago. 2019.

VALLE, I. R. Os herdeiros: uma das principais teses da sociologia francesa. In: VALLE, I. R. et al. Heranças da sociologia de Pierre Bourdieu e Jean Claude Passeron 50 anos de os herdeiros. Curitiba: CRV, 2015b. p. 119-132.

VALLE, I. R. et al. Apresentação. In: VALLE, I. R. et al. (orgs). Heranças da sociologia de Pierre Bourdieu e Jean-Claude Passeron 50 anos de os herdeiros. Curitiba: CRV, 2015b. p. $5-12$.

VALLE, I. R. Por que ler Os herdeiros meio século depois? In: BOURDIEU, P.;

PASSERON, J. C. Os herdeiros: os estudantes e a cultura. 2. ed. Florianópolis: EDUFSC, 2018. p. 9-12.

Submetido em 9 de junho de 2021.

Aprovado em 5 de agosto de 2021.

Desenvolvimento Humano (MINEDH), daí a adoção de duas siglas diferentes para a mesma entidade, em função do contexto temporal em que cada um dos documentos foi produzido.

Rev. Ed. Popular, Uberlândia, v. 20, n. 3, p. 103-121, set.-dez. 2021. 